\title{
O GRAU ZERO DA ARQUITETURA NA ERA FINANCEIRA
}

PEDRO FIORI ARANTES*

\section{RESUMO}

A arquitetura contemporânea experimenta uma arriscada fusão com a publicidade e a indústria do entretenimento. A forma arquitetônica está sendo explorada em seus limites materiais, até a inversão de seus fundamentos construtivos e produtivos, num jogo de volumes e efeitos, aparentemente sem regras e limitações, em busca do grau máximo da renda. Este artigo interpreta essa nova condição da arquitetura - da formação do fetiche e do capital fictício aos canteiros de obra -, tomando como fio condutor a produção do arquiteto Frank Gehry. A análise das formas, técnicas e materiais nos permite investigar por que a arquitetura de ponta é hoje uma das vanguardas da economia rentista.

\author{
PALAVRAS-CHAVE: arquitetura contemporânea; economia rentista; \\ fetiche; Frank Gehry.
}

\section{ABSTRACT}

Contemporary architecture is caught in the risky fusion of marketing and the entertainment industry. The exploration of architectural form pushes the limits of materials to the point of inverting the principles of construction and production, in a play of volumes and effects apparently without rules and limitations, in a search for the highest possible rent. This article interprets this new condition of architecture - from the formation of fetish and fictitious capital to the building site - , focusing on the production of Frank Gehry. The analysis of form, techniques, and materials allows us to investigate why cutting-edge architecture is today one of the vanguards of the rentist economy.

KEYWORDS: contemporary architecture; rentist economy; fetish; Frank Gehry.

[*] Agradeço os comentários e sugestões de Sérgio Ferro, Jorge Oseki, Jorge Grespan, Guilherme Wisnik, e Paulo e Otília Arantes.

[1] O termo é empregado no documentário de Sidney Pollack, Sketches of Frank Gehry (2005, 84 min.)

[2] Herzog, Jacques apud Galiano, Luis Fernández. "Diálogo ylogo:Jacques Herzog piensa en voz alta". Arquitectura Viva, n. 91, ago. 2003, p. 26.
Já faz algum tempo que a arquitetura embarcou no universo midiático das logomarcas, a ponto de as obras serem concebidas para gerar rendas de um novo tipo, que não apenas a velha renda fundiária. Os novos edifícios são desenhados para circular como se fossem logotectures - na expressão de Frank Gehry' , uma das estrelas de maior brilho do atual establishment da arquitetura, autor do celebrado Guggenheim de Bilbao.É o que reconhece também, sem meias palavras, outro arquiteto de grife, Jacques Herzog, um dos responsáveis pelo projeto da New Tate: "Se a arte e a arquitetura são agora mais do que nunca instrumentos políticos é porque estão cada vez mais próximas do universo das marcas" 2 . A sofisticação técnica ostensiva, a diferenciação das superfícies e a exuberância formal passaram a ser requisitos para constituir imagens arquitetônicas exclusivas, capazes de valorizar os investimentos e, conseqüentemente, as cidades que os disputam. 
Com a passagem da hegemonia do capital industrial para a dominância financeira, surgem, nas novas paisagens urbanas, figurações surpreendentes produzidas poruma arquitetura de ponta - aquela que explora os limites da técnica e dos materiais, quase sem restrições, inclusive orçamentárias. O que se vê por toda parte são formas que aparecem como o exato contrário da sobriedade tectônica e espacial, submetida via de regra ao rigor da geometria euclidiana, que dominava a arquitetura moderna. Em sua "liberdade" inventiva, alimentam-se, nesta nova fase do capitalismo, de um paradoxo técnico-formal: quanto mais informe, retorcido, "desconstruído" ou "liquefeito" o objeto arquitetônico, maior seu sucesso de público e, portanto, seu valor como imagem publicitária. Este, o grau zero da arquitetura, reduzido a um jogo de formas, aparentemente sem regras e limitações de qualquer espécie, em busca do grau máximo da renda - fenômeno de que nos ocuparemos aqui.

\section{AFINIDADES ELETIVAS}

Não será demais lembrar que o movimento moderno na arquitetura, desde seus primeiros manifestos, na década de 1920, definiu um programa que elegia como principal aliado, e exemplo a ser seguido, o capital industrial - mais adiante, o próprio Estado e, na periferia, as "burguesias nacionais" e seus governos desenvolvimentistas. Da engenharia à estética industrial, a inspiração maquinista e racionalista norteou suas experiências construtivas e urbanísticas. Mesmo em caráter experimental, eram, quase sempre, projetos para serem multiplicados, em escala de massa. Daí a afinidade com a seriação industrial, mesmo que pouco realizada na prática. Concreto, aço, vidro eram os novos materiais empregados nas formas prismáticas, em geral ortogonais e abstratas, despidas de ornamentos. Tornaram-se objeto de pesquisa e projeto os edifícios industriais, de escritórios, grandes infra-estruturas e casas operárias ("máquinas de habitar") - componentes do capital fixo e do fundo de reprodução da força de trabalho que integram o processo produtivo inerente à acumulação capitalista. A cidade, de seu lado, era pensada como um tecido urbano relativamente uniforme, separado apenas por suas funções, um modelo no qual a renda diferencial intra-urbana tenderia a zero.

O capital industrial e o trabalho assalariado representavam o pólo moderno, enquanto o proprietário fundiário e sua renda da terra (heranças do Antigo Regime e promotores da irracionalidade urbana), o arcaico. Na disputa pela repartição da mais-valia, a arquitetura moderna fez aliança com os setores produtivos, com o capital enquanto função, mais do que como propriedade. Tal simbiose, contudo, foi a rigor mais estilizada do que efetiva com os ramos industriais mais avançados, sobretudo o setor automobilístico, porém ocorreu de fato com as grandes construtoras e governos modernizadores, em cujos canteiros de obra o que vigorava era mesmo a mais retrógrada exploração.

1760 GRAU ZERO DA ARQUITETURA NA ERA FINANCEIRA PEDRO FIORI ARANTES 
[3] Segundo David Harvey, não apenas a arquitetura, mas todo o campo cultural privilegia as rendas monopolistas. As mercadorias culturais possuiriam uma dinâmica diferenciada em relação às mercadorias convencionais, pois sua linguagem de excepcionalidade, originalidade, autenticidadeé decisiva para o estabelecimento das rendas (Cf. "El arte de la renta: la globalización y la mercantilización de la cultura". In: Capital financiero, propriedad inmobiliaria y cultura. Barcelona: Universidad Autónoma de Barcelona, 2005).

[4] Adoto o termo em referência à noção de "trabalho improdutivo" para Marx, isto é, aquele que não gera diretamente mais-valia e que se apóia, justamente, na sua distribuição e partição.

[5] Herzog apud Galiano, op.cit, p. 29.
$\mathrm{Na}$ arquitetura contemporânea, se a aliança novamente é com os setores dominantes, ou seja, com o pólo mais dinâmico e próspero da economia, ela se verifica desta vez com o próprio capital financeiro, e em particular com a indústria do entretenimento e a nova "economia do acesso", baseada na renda. Na verdade, a associação histórica da arquitetura sempre foi com os donos do poder e do dinheiro, sobretudo com a propriedade privada, da terra e do capital. Existe uma tendência da arquitetura em se apegar às rendas e não aos lucros, dada sua fixidez e seu custo elevado3. É quase uma "fatalidade" da sua natureza: ela reitera o fundiário e o financeiro, mesmo que não o faça voluntariamente. Por ser um bem único, sempre detém alguma renda de monopólio. Na arquitetura moderna, havia uma contratendência que procurava minimizar o poder da renda e das finanças, associando-se aos setores produtivos e governos nacionais modernizadores, mas na era da mundialização financeira não há mais nenhuma força que contrarie esse poder. Como veremos, as implicações no plano das dimensões construtivas e sociais da arquitetura serão profundas: a arquitetura rentista abdica de certos conteúdos em benefício de usos "improdutivos"4, próprios à esfera da circulação e do consumo (terminais de transporte, shoppings centers, hotéis, estádios, museus, salas de concerto, parques temáticos etc.).Seu desejo nãoé mais de seriação e massificação, mas de diferenciação e exclusividade. Produz objetos únicos e marcantes que "pousam" nas cidades potencializando a renda diferencial e o capital simbólico.

\section{ARQUITETURA DE MARCA}

$\mathrm{Na}$ virada do século XXI, os arquitetos do star system passaram a desenvolver imagens cada vez mais elaboradas do poder e do dinheiro. Com a palavra novamente Herzog: "trabalhamos com a materialidade física da arquitetura porque só assim podemos transcendê-la, ir mais longe e inclusive chegar ao imaterial". ${ }^{5}$

Alcançar o "imaterial" por meio da mais tectônica das artes, a arquitetura - um aparente contra-senso - é produzir um valor intangível socialmente mensurável, como o valor de representação de um poder corporativo (de um governo, de uma empresa, de uma igreja ou de um país). A diferença é que, agora, essa força espetacular da arquitetura não é mais requisito único de regimes absolutistas, autocráticos ou fascistas, mas de grandes estratégias de negócio associadas ao turismo, a eventos culturais e esportivos, ao marketing urbano e à promoção de identidades empresariais. O fato é que nenhum arquiteto moderno, diante de suas (agora) prosaicas caixas de vidro, aço e concreto, poderia ter antecipado o grau de sofisticação técnica e exuberância formal que a "arquitetura de marca" está alcançando. 
A ascensão das marcas, mesmo as de empresas produtoras de mercadorias tangíveis, está sobretudo associada à nova hegemonia financeira, segundo a qual a imagem e o nome da marca sobrepõem-se ao valor-trabalho das mercadorias que a empresa produz (ou terceiriza), acrescentando-lhes um valor de novo tipo: uma espécie de renda de representação das próprias mercadorias. Cumprem, como imagem que se destaca do corpo prosaico do objeto, um papel similar ao da abstração do dinheiro. O diferencial de exclusividade da marca é justamente ser uma forma de propriedade que não pode ser generalizada. $O$ monopólio sobre o seu uso é uma forma de renda, por isso ela é patenteada e, de forma correlata à terra,é protegida porcercas jurídicas (e por vezes reais) para controle do acesso. Essa autonomização das formas de propriedade produz, simultaneamente, uma autonomização da forma como pura propriedade.A forma se torna capital por meio de um fenômeno imagético, no qual é remunerada como capital simbólico, por uma espécie de renda do olhar.

A expansão da lógica do capital portador de juros sobre todas as outras esferas da economia e da cultura se exprime, no campo da produção das mercadorias, através de uma espécie de autonomização do significado em relação à materialidade dura dos produtos. A racionalidade do capital fictício é, assim, a troca de um produto imaginário por dinheiro, é a transformação em capital daquilo que originalmente não é. Segundo Naomi Klein, as grandes corporações raciocinam que:

todo mundo pode fabricarprodutos [...] essa tarefa ignóbil pode serdelegada a terceiros [...] enquanto as matrizes estão livres para se concentrar em seu verdadeiro negócio - criar uma mitologia corporativa poderosa o bastante para infundir significado a esses toscos objetos apenas assinalando-os com seunome. ${ }^{6}$

Essa busca pela "transcendência corporativa" é um fenômeno relativamente recente, quando um grupo seleto de empresas percebeu que construir e fortalecer suas imagens de marca, numa corrida pela ausência de peso, era a estratégia para alcançar um novo tipo de lucratividade7. "Esses pioneiros declaram audaciosamente que produzir bens era apenas um aspecto incidental de suas operações", afirma Naomi Klein, "pois sua verdadeira meta era livrar-se do mundo das coisas". Ou procurar "fazer crer que cada produto adquiria um estatuto superior ao de coisa", como se tivesse uma "alma", um "núcleo espiritual". ${ }^{8}$

A estratégia estava dando certo, pois as empresas que investiam na capitalização de suas marcas passaram a inflar como balões e a valer no mercado várias vezes mais do que no papel - numa impressionante capitalização fictícia. Mesmo que seguissem produzindo (cada vez menos diretamente) mercadorias palpáveis, seus lucros se
[6] Klein, Naomi. Sem logo: a tirania das marcas em um planeta vendido. Rio de Janeiro: Record, 2004, p. 46.

[7] É bom lembrar, no entanto, que essa estratégia não decorre exclusivamente da atual dominância financeira no regime de acumulação. A possibilidade de desviar lucros diferenciais da taxa média remonta, no fundo, à própria órbita produtiva: as formas rentistas de hoje estão, naverdade, exponenciando mecanismos de concorrência entre capitais, sobretudo quando fabricam diferenças imaginárias para abocanhar uma porção maior do lucro total.

[8] Ver Klein, N., op.cit., cap.I; Fontenelle, Isleide. $O$ nome da marca. São Paulo: Boitempo, 2004, pp. 177 e 180. 
[9] Ambos são termos utilizados por Isleide Fontenelle.

[10] Harvey, op.cit.

[11] Prado, Eleutério da Silva.Desmedida do valor: crítica da pós-grande indústria. São Paulo:Xamã, 2005.

[12] Chesnais, François. “Aemergência de um regime de acumulação financeira". Praga, n. 3, São Paulo, 1997, p. 37. elevavam muito acima da média porque tinham se tornado verdadeiros "agentes produtores de significados", como se fizessem parte da indústria cultural.

Parece que estamos presenciando uma espécie de "deslocamento" ou "mudança de estatuto" da forma-mercadoria9. Além de gerar maisvalia por meio do trabalho, ela crescentemente aufere rendas, assumindo a condição de mercadoria cultural — por natureza, distinta da mercadoria prosaica e, por isso, portadora de uma renda adicional, de tipo monopolista ${ }^{10}$. Mais que isso, o fato de cada empresa produzir mercadorias supostamente exclusivas limita as possibilidades de comparação entre produtos e trabalhos equivalentes. A própria medida de "trabalho socialmente necessário" estaria, assim, deixando de expressar o valor, que passaria a sofrer uma "desmedida". ${ }^{11}$

A articulação entre renda e lucro no interior das mercadorias introduz na lógica produtiva uma dinâmica nova, um "traço rentista" que não deve ser subestimado. Segundo François Chesnais, dentro da contabilidade das "empresas-rede" passou a ocorrer uma "'confusão' das fronteiras entre o 'lucro' e a 'renda" ${ }^{12}$. Não por acaso, a "gestão de marcas" tornou-se a especialidade preocupada justamente em definir o ponto ótimo dessa combinação lucro-renda.

$\mathrm{Na}$ arquitetura não é diferente. Os arquitetos da era financeira, ao contrário dos modernos, não procuram soluções universalistas, para serem reproduzidas em grande escala - o que anularia o potencial de renda monopolista da mercadoria. O objetivo é a produção da exclusividade, da obra única, associada às grifes dos projetistas e de seus patronos. O sucesso estrondoso de algumas obras e seus arquitetos, contudo, acaba estimulando a repetição das mesmas fórmulas projetuais, reduzindo a cada "duplicação" de volumetrias similares sua competência em gerar "rendas de exclusividade". A arquitetura de marca tem, assim, um limite comercial que a obriga a adotar soluções inusitadas e sempre mais chamativas: se diversas cidades almejarem uma obra de Frank Gehry, por exemplo, perderão progressivamente a capacidade de capturar riquezas por meio de projetos desse tipo.

\section{DUPLO FETICHISMO}

Ao caracterizar a "sociedade do espetáculo" como o estágio avançado do capitalismo no qual tudo virou "representação", Guy Debord estava justamente apontando para o fato de que a práxis social teria definitivamente se cindido entre realidade e imagem. O espetáculo é, pois, a antihistória, o antitrabalho e a antipolítica. Trata-se de um mundo tautológico em que os meios se confundem com os fins, uma gestão de abrangência máxima das condições da existência por uma segunda realidade imaterial, separada, mas integrada. O termo "espetáculo" já tinha 
sido adotado por Benjamin para definir a estetização da política como prática central do fascismo. Debord, entretanto, completa o argumento definindo o espetáculo não apenas como manifestação de regimes totalitários, mas do próprio capital. Na sua definição mais conhecida, "o espetáculo é o capital em tal grau de acumulação que se torna imagem". ${ }^{13}$

A descrição que passou a se generalizar a partir da década de 1970 é a de que viveríamos uma transição da modernidade para a chamada "pós-modernidade" - com uma correspondente transição da centralidade da lógica econômica da produção para a circulação e o consumo. A capacidade de controle acurado sobre a forma e sobre a imagem passa, em conseqüência, a ser um elemento decisivo. Presenciamos, por isso, a inflação vertiginosa do design. "O sistema de valor de troca se estendeu a todo o domínio dos signos, formas e objetos [...] em nome do design", afirma Baudrillard. Imagem e produto podem circular como uma coisa só, como produtos-imagem com "signos valores de troca" ${ }^{14}$. Segundo Hal Foster, nessas condições, o produto não é mais um objeto, mas um dado a ser manipulado. ${ }^{15}$

Essa transformação é contemporânea da expansão da financeirização como fenômeno hegemônico global.É o momento em que a lógica do capital fictício passa a comandar a das forças produtivas reais, como previra Marx, em $O$ capital. O tempo e a forma do capital portador de juros passam a se impor sobre os demais e servem como nova medida. De um lado, o tempo se projeta para a frente, com o juros comandando, de forma ditatorial, a expectativa de lucros futuros e as decisões do presente. De outro, a forma-dinheiro deixa de estar articulada com seu conteúdo, descolando-se de seu fundamento.A dominação parece não ter sujeito e o capital, estar desgarrado. Mas só parece, como veremos.

Essa transformação, descrita por Marx no Livro III sob a denominação de "fetiche-dinheiro" ou "fetiche-capital" ${ }^{16}$, estabelece uma forma complementar ao "fetichismo da mercadoria", apresentado no início do Livro I.

O fetiche em sua primeira manifestação, como fetichismo da mercadoria, é a separação entre o fazer e o feito, a autonomização do produto em relação ao produtor. O encantamento da mercadoria, que parece nascida por iniciativa própria, negando sua origem, é uma abstração primeira. O exemplo dado por Marx é o da mesa que passa a dançar, como numa sessão espírita. Esse fetiche de primeiro grau está associado à formação de valor na produção de mercadorias, bens tangiveis que cristalizam a energia do trabalho fisicamente aplicado.

O fetiche em segunda potência, o fetichismo do capital, é uma abstração sobre outra abstração, uma forma de autonomização da propriedade e de sua representação. Essa segunda abstração não é mais interna à mercadoria, como no primeiro caso, mas aparece como uma força externa, de um tempo que corre à frente e define novos espaços e
[13] Debord, Guy. A sociedade do espetáculo. Rio de Janeiro: Contraponto, 1997, p. 25.

[14] Baudrillard, J. apud Foster, Hal. Design and crime (and other diatribes). London: Verso, 2002, p. 18 (tradução minha).

[15] Foster, op. cit., p. 21 (tradução minha).

[16] Marx, K. O capital. São Paulo: Abril Cultural, 1998, t. 1, liv. III, cap. XXIV, em especial, p. 284 . 
[17] Ibidem, p. 279.

[18] Debord, op.cit., p.34.

[19] Marx, O capital, op. cit., t.., liv. I, p. 146 .

[20] Fredric, Jameson. "O tijolo e o balão: arquitetura, idealismo e especulação imobiliária". In: $A$ cultura do dinheiro: ensaios sobre a globalização. Petrópolis: Vozes, 2001, p. 173.

[21] O ensaio, de 1976, foi revisado e republicado em Arquitetura e trabalho livre. São Paulo: CosacNaify, 2006. formas. No fetichismo do capital, o dinheiro parece gerar mais dinheiro a despeito da produção e do trabalho, como se o valor nascesse da própria circulação. Esta segunda abstração passa a sobredeterminar a primeira, como forma mais acabada de exposição. Segundo Marx, nesse momento o fetiche encontra sua "forma pura" e "não traz nenhuma cicatriz, nenhuma marca do seu nascimento". ${ }^{17}$

Pode-se afirmar que, de forma similar à autonomização do dinheiro em relação à mercadoria, ocorre a da imagem em relação ao objeto - ambas são manifestações do fetiche em sua forma potencializada. A imagem também se torna um ativo financeiro, como uma renda que adquire uma figuração. Como afirma Debord,

o espetáculo é a outra face do dinheiro: o equivalente geral abstrato de todas as mercadorias [...] o espetáculo éo dinheiro que apenas se olha, porque nele a totalidade do uso se troca contra a totalidade da representação abstrata. ${ }^{18}$

Se o primeiro fetiche ainda estava preso à produção do valor e ao mundo de Prometeu - ou seja, à liberação de forças produtivas, ao "fogo do trabalho" que lambe as matérias inanimadas despertandoas ${ }^{19}$ - no fetiche de segundo grau, prevalece o reino de Midas: tudo que o dinheiro toca passa a reluzir, tal qual sua imagem, ao mesmo tempo em que se desumaniza - o processo de acumulação desprende-se de seus fundamentos.

Na produção da cultura e, no caso da arquitetura, a passagem da primeira para a segunda forma de fetiche tem conseqüências importantes. Como afirma Fredric Jameson, "há uma diferença radical no papel da abstração no modernismo e no pós-modernismo"20. A abstração pós-moderna está associada à financeirização que, no âmbito da produção do espaço, encontra como equivalente ao capital portador de juros, e intimamente ligado a ele, a especulação imobiliária e suas rendas. O problema colocado por Jameson é o de definir as novas mediações entre economia financeira/rentista e inflação cultural, levando-se em conta a especificidade da arquitetura.

O fetichismo de primeiro grau, na crítica de arquitetura,é um verdadeiro tabu, enfrentado por poucos. Creio que devemos ao arquiteto Sérgio Ferro a interpretação mais contundente desta verdadeira interdição, em seu ensaio sobre "O canteiro e o desenho" ${ }^{21}$. A dificuldade passava por definir a arquitetura como uma fusão entre arte e mercadoria,como protagonista na produção do valor, o quelhe permitia ser decifrada segundo a interpretação de Marx. A crítica ao fetiche da mercadoria na produção da arquitetura permitiu vislumbrar um espaço até então oculto: o canteiro de obras. A contradição desenho-canteiro, que está na base da separação entre os produtores e seu produto,éo mote da crítica de Sérgio Ferro. Como a produção da arquitetura ainda está pró- 
xima do saber da mão - éuma forma de manufatura que não tem como se automatizar e tampouco realiza produtos em séries infinitas como na indústria -, ela instaura outras separações, dada a ausência da mediação mecânica. Sérgio Ferro aponta duas principais: a mediação formal do desenho, composições, rigor geométrico, jogo de volumes e texturas, sistemas de medidas; $\mathrm{o}$ a a agamento das marcas do processo de produção, sobretudo por meio da dissimulação dada pelo revestimento, como uma capa que encobre o índice do trabalho - segundo ele, parte do segredo para fazer do trabalho concreto, abstrato. O oficial de revestimentos seria, por isso, o "mais trágico" dos operários, cabendo a ele "com sua mão treinada, leve, pela carga de muita sabedoria, acariciar até o polimento a superfície em que desaparece". ${ }^{22}$

Em seus textos mais recentes, Sérgio Ferro também nota que a mudança na natureza do fetiche torna insuficiente a crítica à alienação do produtor para explicar a produção contemporânea. As utopias modernas, segundo ele, mal ou bem sempre foram "construtivas", em consonância com os avanços da indústria e da engenharia. Nos projetos arquitetônicos de hoje, os preceitos construtivos convencionais são ironizados por aberrações elementares, tramas embaralhadas, geometrias não-euclidianas, pilares inclinados, curvas oblíquas, volumes irregulares, cascatas de formas aleatórias. Um poço sem fundo da autonomia formal que irá encontrar nas novas ferramentas tecnológicas de projeto a possibilidade de transladar o gesto artístico em processo produtivo factível no canteiro de obras. O desenho no computador aumenta sua força e permite figuras que antes seriam irrealizáveis com régua e compasso. A arquitetura pende para o escultórico e a imagem da obra acabada torna-se um evento midiático.

A arquitetura pós-moderna, ou "simulada" 23 , ao incorporar recursos e expedientes da mídia, principia, decididamente e quase ao pé da letra, a desmaterializar-se. Nesse contexto, ocorre uma exacerbação do formalismo, uma reabilitação do frívolo, um predomínio do significante sobre o significado, enfim, estamos diante de uma arquitetura em que o "fútil assume proporções metafísicas" 24. Malabarismos formais convertidos em apoteose publicitária dão origem a uma tectônica que não guarda mais relação com a escala humana e com a estática dos objetos. Segundo Peter Fuller, trata-se de "um fluxo de imagens que parecem mais reais do que a própria realidade", o que dá "a impressão de um mundo físico em que as coisas foram desmaterializadas ou reduzidas a superfícies" 25 . O design das mercadorias, dos objetos mais simples aos edifícios mais complexos, passa por uma expansão da estética das aparências, das embalagens e das "peles", cada vez mais sofisticadas e chamativas, num "obsceno reino chapado das superfícies", na expressão de Otília Arantes, em que a mera provocação da imagem desmancha qualquer propósito construtivo.
[22] Ibidem, p. 130.

[23] A expressão "arquitetura simulada" é adotada, por Otília Arantes, em O lugar da arquitetura depois dos modernos (São Paulo: Edusp, 1994).

[24] Ibidem, p. 65.

[25] Apud ibidem, p. 51. 
Sai de cena Le Corbusier, com seu "modulor" e suas "máquinas de morar", e entra Frank Gehry, o arquiteto ícone da pós-modernidade financeira. Como Midas, ele tem a capacidade de transformar seus prédios, amontoados irregulares de aço, titânio e vidro, em verdadeiras minas de ouro. Sua clientela, como se verá nas análises a seguir, já não são os Citroën e Vargas, de Le Corbusier.

\section{UM MESTRE DA INSTABILIDADE}

A primeira grande tentativa de Frank Gehry de realizar uma fusão entre arquitetura e marketing deu-se no projeto do Walt Disney Concert Hall, no centro de Los Angeles. O projeto de Gehry, datado de 1988, pretendia se destacar radicalmente de seu entorno, cercado por imensas torres de escritório. Era uma dobradura irregular, em placas reluzentes de aço, como uma caixa encouraçada que fosse explodida pelo impacto de um bólido. O paradoxo visual residia na fluidez completa das formas recobertas por uma superfície dura, típica de blindagem militar. As junções complexas entre volumes e suas curvaturas dissimuladas eram, entretanto, um desafio construtivo que punha à prova o conhecimento da engenharia. $O$ projeto foi considerado inexeqüível pelas construtoras consultadas pela Disney, que suspendeu sua execução.

Gehry, entretanto, não desistiu da empreitada e foi descobrir na indústria aeroespacial francesa um programa de modelagem digital que pudesse transformar sua ousadia escultórica em um edifício exeqüível. O CATIA, da Dessault Systèmes, permitiu que as maquetes de criação de Gehry, feitas de papelão, massinhas de modelar e folhas de alumínio, pudessem ser esquadrinhadas e lidas a laser. O programa transformava as maquetes em grids tridimensionais, definindo coordenadas que permitiam detalhar a estrutura, peças e superfícies, e testar o seu comportamento estático. O CATIA, que nos anos seguintes acabou sendo difundido porvários setores industriais, inclusive o de animação para cinema, era capaz de trabalhar de forma avançada com planos e peças irregulares, entendidos como superfícies complexas e não-euclidianas.

Ainda assim, a Disney não estava completamente certa de seu investimento. Foi graças à parceria com o mais agressivo homem de negócios da cultura, Thomas Krens, diretor do Museu Guggenheim, que Gehry pôde construir de fato suas gigantescas flores metálicas. Em 1997, Gehry inaugura o projeto que se tornou um verdadeiro emblema arquitetônico da globalização:o Museu Guggenheim de Bilbao. O museu é uma espécie de navio de guerra cubista, ancorado no rio Nervión, recoberto com chapas de titânio que reluzem ao sol como ouro. Gehry decompôs o campo perspéctico em múltiplos pontos de fuga que dão a sensação de movimento e instabilidade. 
Gehry talks: architecture + process. New York, Universe, 2002.
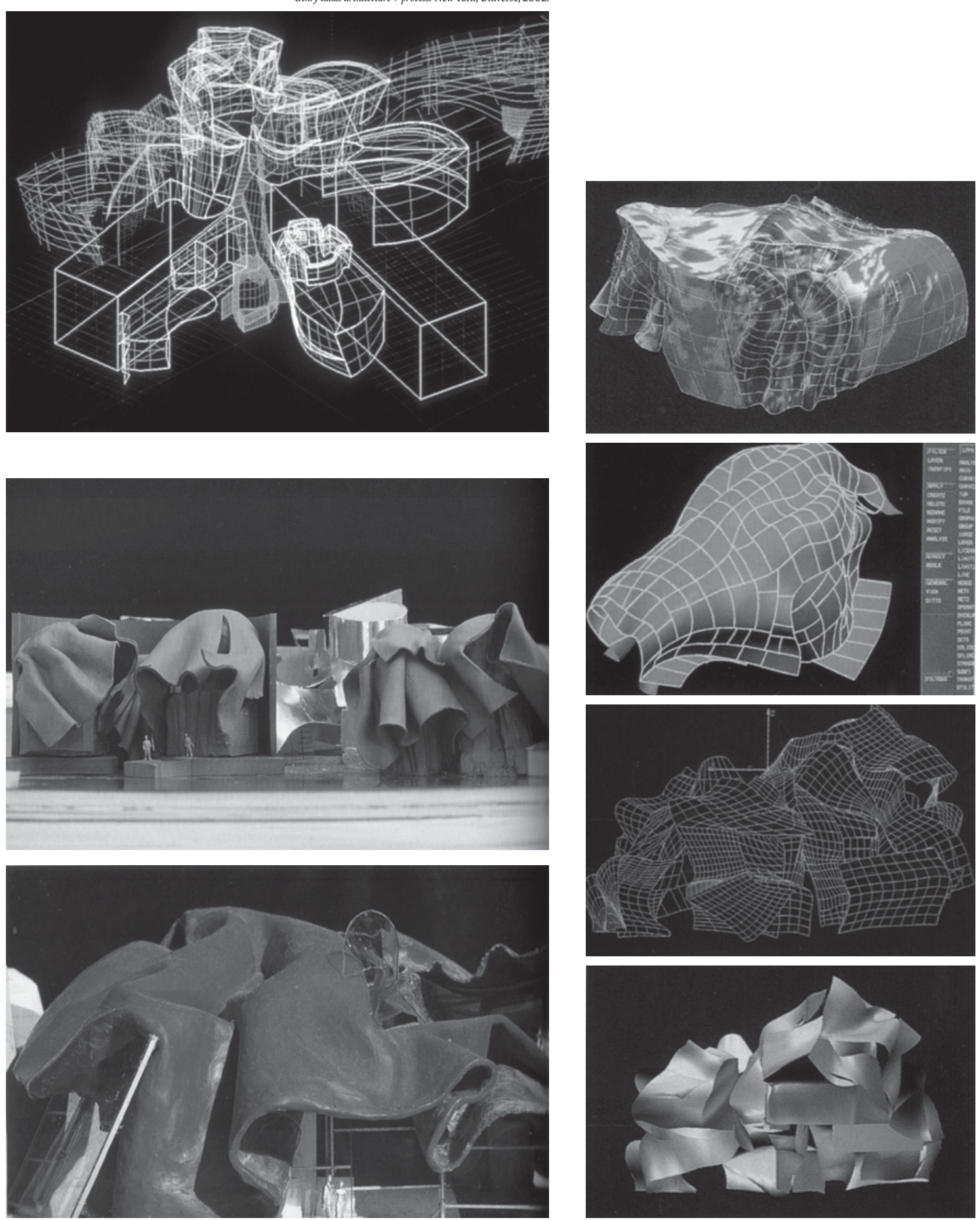

Maquetes de criação de Frank Gehry, feitas de papelão, massinhas de modelar e folhas de alumínio. A liberdade plástica do arquiteto-escultor, com suas formas únicas e espetaculares, é requisito para a criação de rendas de monopólio.

As maquetes são quadriculadas a laser e transportadas para um software da indústria aeroespacial capaz de calcular geometrias construtivas não-euclidianas, estudar seus comportamentos estruturais e detalhar componentes. 

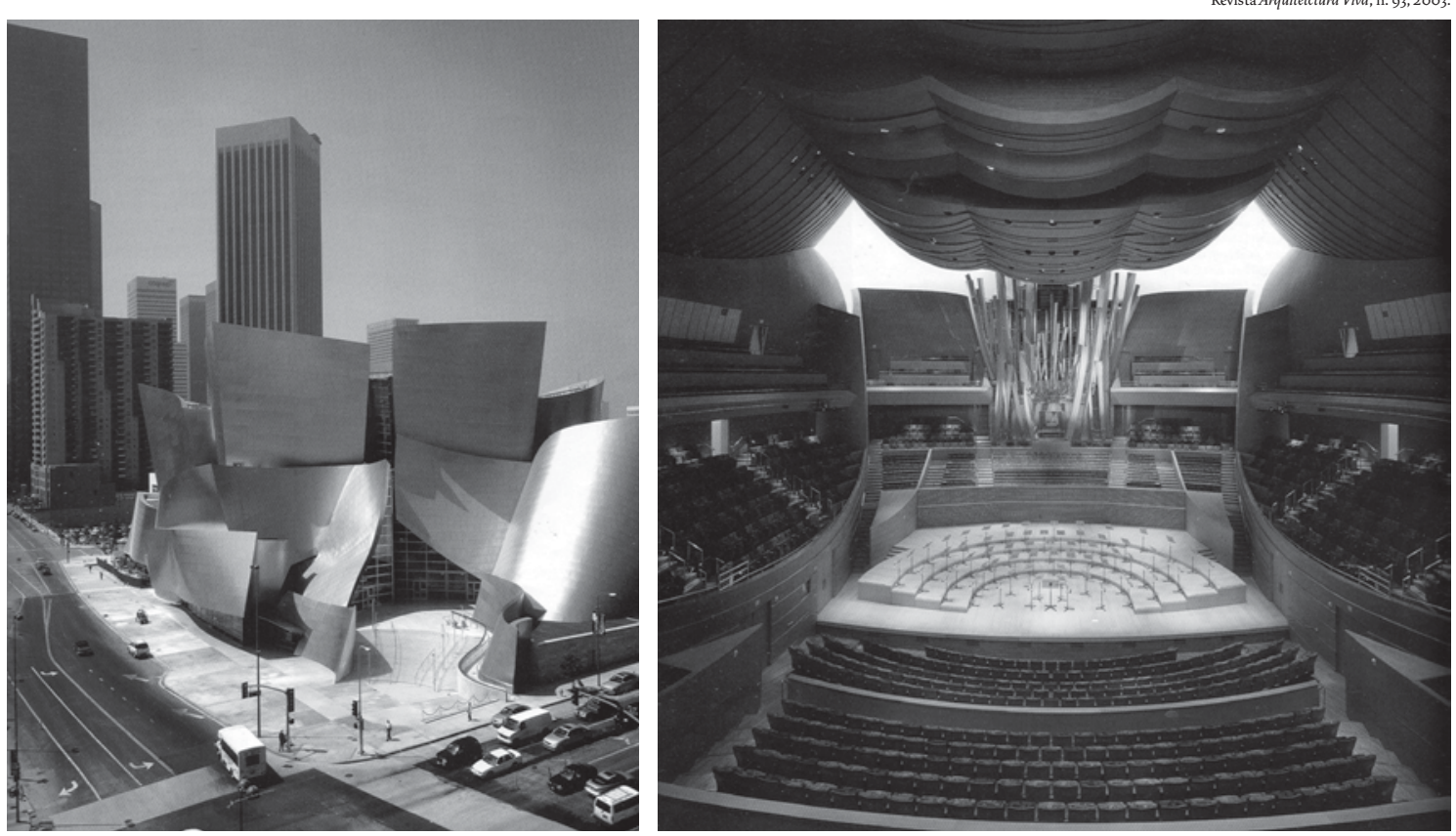

Frank Gehry, Walt Disney Concert Hall, Los Angeles, 1988-2003. O projeto, à época, foi considerado inexeqüível. Após o sucesso estrondoso de Bilbao, a megacorporação de entretenimento autorizou sua construção.

DALCO, Francesco e FOSTER, Kurt. Frank Gehry. Complete works. New York, The Monacelli Press, 1998.

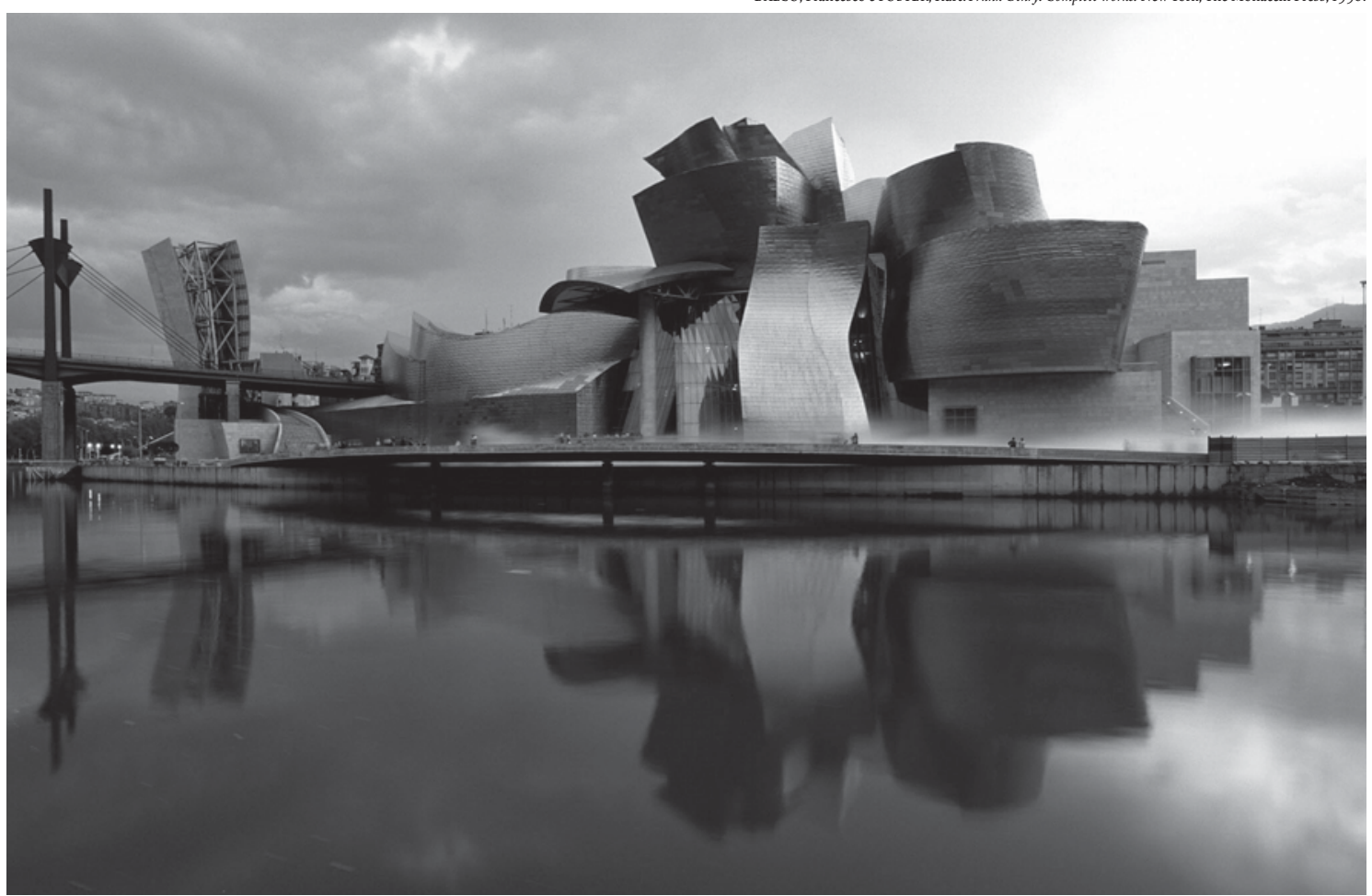

Frank Gehry, Museu Guggenheim, Bilbao, 1991-1997. O museu é o resultado mais bem sucedido de co-branding urbano até o momento. A iniciativa pioneira foi capaz de capturar a super-renda imagética da operação, enquanto outras cidades e corporações corriam atrás da mesma estratégia. 
Revista Arquitetctura Viva, n. 107-8, 2006.
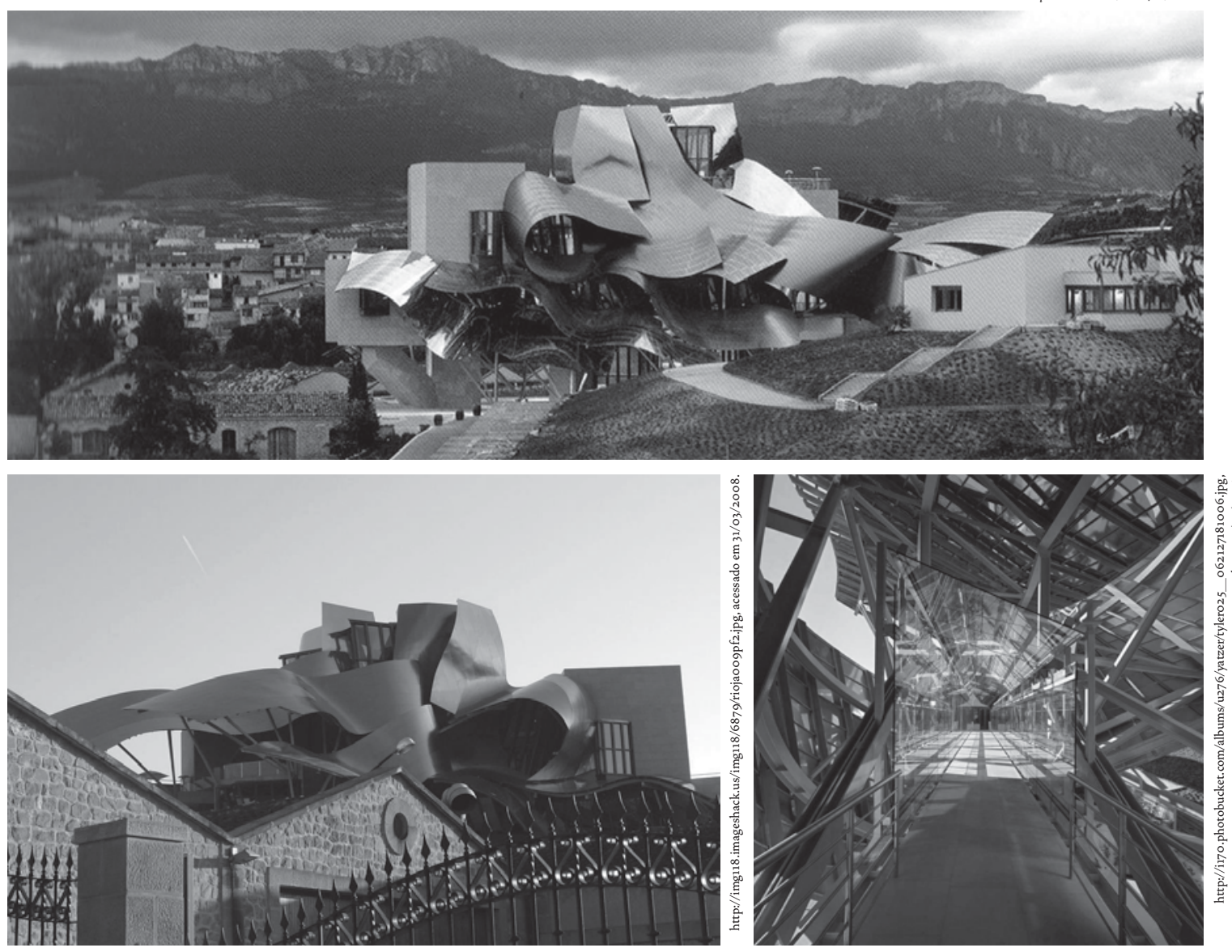

Frank Gehry, Hotel do Vinho, Casa Marquês de Riscal, Elciego, 2001-2006. A obra brota em meio à cidade medieval como um jorro de vinho espalhando ondulações e reflexos metalizados, numa figuração rentista do borbotão de riquezas emergindo da terra.
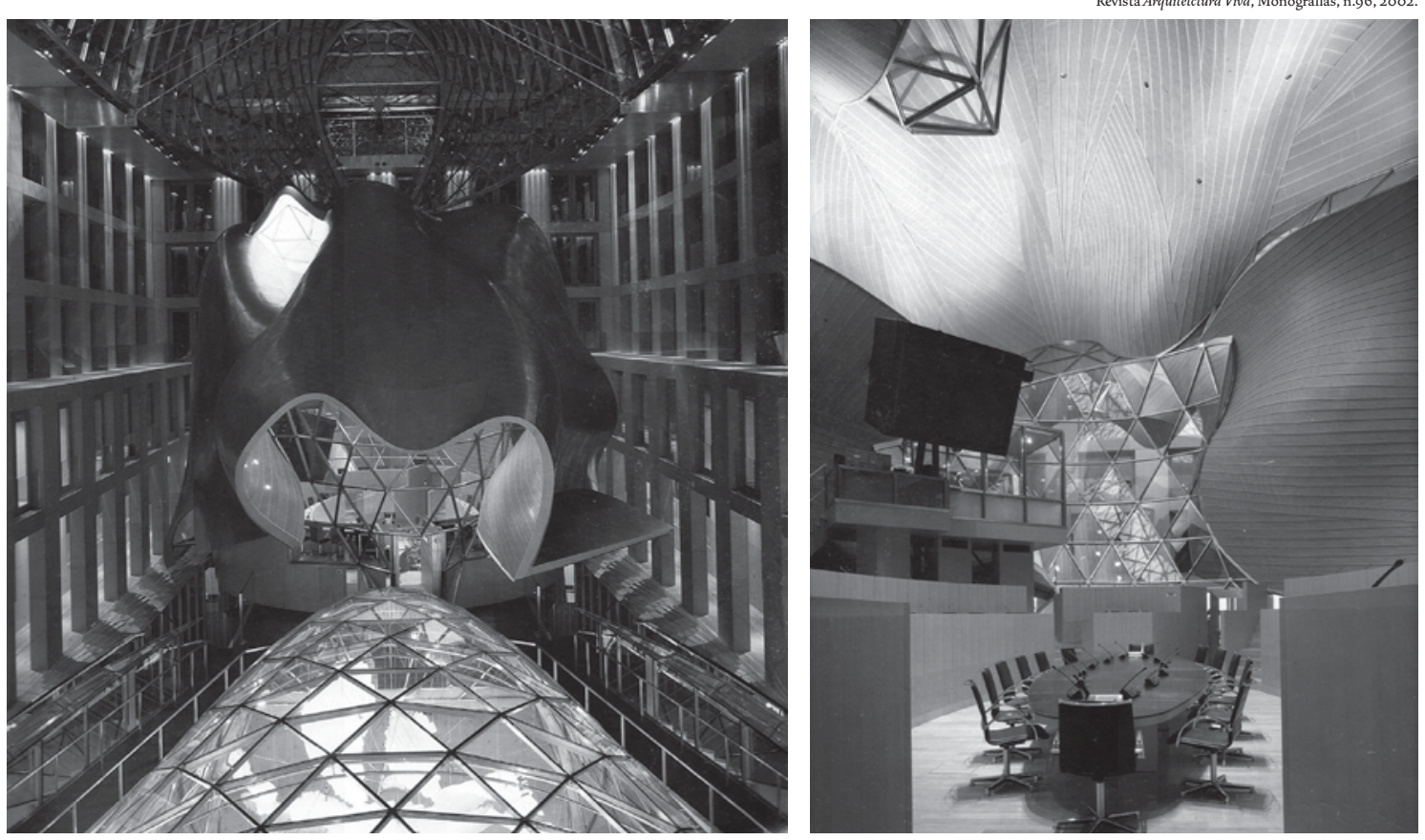

Frank Gehry, DG Bank, Berlim, 1994-2001. No pátio central do prédio, uma cobertura irregular reluzente faz alegoria ao capital financeiro. Abrigada sob essa resplandecente massa informe, espécie de coração do sistema, encontra-se a mesa do board. 

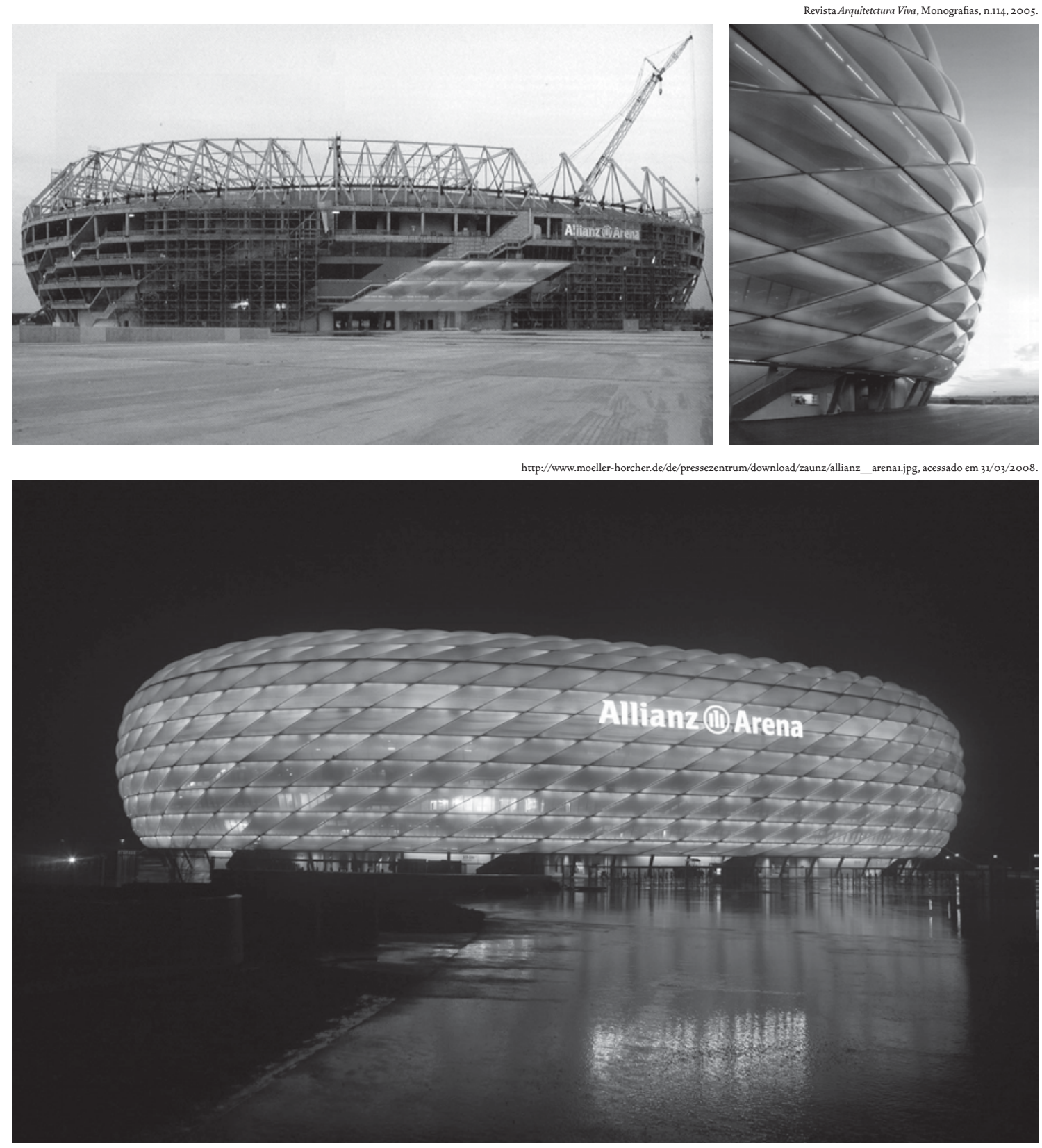

Jacques Herzog e Pierre de Meuron, Allianz Arena, Munique, 2002-2005. O estádio da Copa de zoo6 é a edificação esportiva mais midiática já construída para um grande evento. Sem a membrana inflável, trata-se de uma estrutura de concreto convencional, mas quando ela começa a ser aplicada, produz-se o estranhamento: o "tijolo" está virando um "balão", na expressão de Jameson. 
Aliberdade formal do museu, no limite do gesto aleatório, expressa a ausência de formas modelares que definiram a espacialidade arquitetônica até recentemente. Trata-se de uma espécie de "instabilidade semiótica" proposital - uma composição inapreensível e que foge das matrizes visuais asseguradoras -, que converge, enfim, para os fundamentos da nova economia e da desestabilização do próprio mundo do trabalho. A fluidificação das formas revela aqui uma real dimensão de classe, se for permitido falar do que afinal está em jogo: a alegação vanguardista corriqueira de que tal "desmanche" representa o fim de referências estáveis e sufocantes não deixa de incluir, como se fosse apenas um detalhe, o desmanche das instituições próprias ao campo do trabalho.

O Guggenheim Bilbao é, por isso, bem-sucedido não apenas como surpreendente aparato técnico/estético, como também, ou sobretudo, enquanto estratégia rentista. Ao ser divulgado pelos canais midiáticos como ápice da produção arquitetônica recente, gerou fabulosas rendas de monopólio para os diversos agentes envolvidos. Como já constatara David Harvey, as intervenções urbanas têm seespecializado em construir "lugares" exclusivos capazes de exercer um poder de atração significativo sobre os fluxos de capita ${ }^{26}$. Neste caso, a obra tornou a decadenteeescura capital basca, que vinha sofrendo com os efeitos da desindustrialização e da crise em seus estaleiros, uma das atrações do turismo mundial. Hal Foster chega a dizer que, depois dessa obra, a arquitetura não foi mais a mesma, e vivemos a cada novo projeto do gênero uma espécie de "Efeito Bilbao" 27 , no qual cada cidade procura construirum espetáculo de magnitude similar com o objetivo de atrair novos fluxos de capital. O museu éo resultado mais bem-sucedido de co-branding urbano até o momento, associando as "marcas" de Guggenheim, Bilbao, Gehry e Dessault numa alavancagem midiática conjunta. A iniciativa pioneira foi capaz de capturar a super-renda imagética da operação, enquanto outras cidades e corporações corriam atrás da mesma estratégia.

A megacorporação de entretenimentos norte-americana, dessa vez, tinha ficado para trás.Após o sucesso estrondoso de Bilbao, a Disney autorizou finalmente a construção de sua Sala de Concertos na capital da Califórnia, inaugurada apenas em 2003, quinze anos após a elaboração do projeto.

A 125 quilômetros de Bilbao, em Rioja, Gehry foi convocado para projetar outra máquina de atração de dinheiro: o Hotel do Vinho, da casa Marquês de Riscal. A "parceria" com o cada vez mais financeirizado mondo vino não foi casual ${ }^{28}$. A iniciativa associa dois tipos de rentismo, o do vinho 29 e o da arquitetura. David Harvey, atualizando o exemplo de Marx, comenta que, na atual indústria globalizada do vinho, não é mais a tradição que garante as maiores rendas aos melhores terroirs, mas a prática discursiva do mercado de experts, ao construir
[26] Harvey, op. cit.

[27] Foster, op. cit., p. 42.

[28] Ver, por exemplo, a descrição da modernização da economia do vinho no documentário Mondovino, de Jonathan Nossiter (2004, $134 \mathrm{~min}$.).

[29] Marx, para explicar a teoria da renda diferencial da terra em $O$ capital, utilizara como um de seus exemplos a produção de vinhos. 
critérios de avaliação de gosto que têm favorecido produtores que modernizam seus métodos e adotam estratégias de marketing. $\mathrm{O}$ novo edifício de Gehry dá status inovador à casa Marquês de Riscal e região, colaborando para o fortalecimento global da marca, ao mesmo tempo em que atrai turistas, enólogos e enófilos para o referido hotel.

A obra de Gehry brota em meio à cidade medieval de sobrados em pedras de arenito como um jorro de vinho espalhando ondulações e reflexos metalizados purpúreos - figuração rentista, tal como um borbotão de riqueza (como a do petróleo) emergindo da terra. O arquiteto faz uma mínima concessão ao arenito local em alguns dos volumes do edifício, mas que são soterrados pelas cachoeiras de metal. As ondas, em tom violáceo e baunilha, fazem uma alegoria às cores e buquês dos vinhos. Há, de fato, um choque total entre edifício e seu entorno, sem qualquer preocupação contextual (contrariando a vertente regionalista/vernacular tão em voga na Espanha).

Esseéum fenômeno recorrente nos projetos contemporâneos, nos quais os edifícios se apresentam como totalidades em si, desgarrandose da cidade, de qualquer contexto ou território. Eles cumprem funções para além do lugar e do local, são edifícios e infra-estruturas transnacionais de circulação do capital. Essa arquitetura torna-se, por isso, auto-referente, tal como as finanças. Daí a irrelevância do contexto - não há mais que se preocupar em formar a cidade, um mundo coeso, eventualmente homogêneo. Assim, pode-se chegar a um verdadeiro "espaço delirante", sem restrições de estrutura, de materiais, recursos e mesmo de qualquer uso. Como afirma Hal Foster,

sem os constrangimentos clássicos da arquitetura (resistência dos materiais, estrutura, contexto), a sua arquitetura rapidamente se torna algo arbitrário e auto-indulgente (por que essas curvas e não outras?) — os fãs de Gehry tendem a confundiressa arbitrariedade com liberdade. ${ }^{3 \circ}$

Em seu recente projeto para o DG Bank, em Berlim, Gehry produz novamente um choque contrastante, dessa vez entre a sobriedade externa do edifício e seu interior surpreendente. No pátio central do prédio ele pousa uma cobertura irregular reluzente (de novo, Midas), que poderia também ser interpretada como uma ironia norte-americana do arquiteto, como se uma derradeira bomba dos aliados tivesse ali sido lançada. Abrigada sob essa resplandecente massa informe, espécie de coração do sistema, está a mesa do board, conectada mundialmente por meio de telões de videoconferência. Quem olha da rua o edifício, não chega a notar a intervenção de Gehry, a menos que entre eveja, por meio da colunata, os reflexos metalizados que vêm do seu coração. Aqui, a alegoria do capital financeiro - um choque de visualidade que cega - é mais sofisticada do que as cascatas de vinho em Rioja. 
Seja pela comparação com o conjunto do edifício do banco, estruturado segundo a forma tríptica convencional (dois pilares e uma viga), ou mesmo pela própria intuição estática que a força da gravidade nos dá, a surpresa formal da intervenção de Gehry impede a compreensão de como foi feita. A massa irregular da cobertura em chapas de cobre aparece como uma mágica, contrariando as regras da física e da engenharia. A cobertura superior do pátio central, toda em vidro, eleva-se acima do gabarito do prédio, como se tivesse sido estufada pela explosão interior do volume em cobre. A forma curvilínea e aerodinâmica é dada por uma espetacular treliça metálica tensionada por cabos de aço. Mais uma vez, a imagem se destaca da tectônica do corpo do objeto, como algo que paira acima da sua banal materialidade.

$\mathrm{Na}$ verdade, há aqui alguns truques. A estrutura do volume central é toda composta por pórticos ondulados em aço. Ela é recoberta por painéis de cobre (externamente) e de madeira (internamente), constituindo superfícies fluidas, que escondem as estruturas e todas as suas artimanhas para permanecer de pé. Uma solução aparentemente ousada, mas que se vale da técnica corriqueira da "armação oculta", normalmente utilizada em esculturas grandes e ocas, como a Estátua da Liberdade, em Nova York. ${ }^{31}$

\section{A PROdução do VAlor segue na base}

Se ainda formos procurar nas obras de Gehry expressões da contradição desenho-canteiro, próprias ao fetiche de primeiro grau, encontraremos diversas - o que comprova, aliás, que um tipo de fetiche não substitui o outro, mas se sobrepõe. Numa comparação com os arquitetos modernos - que desenhavam artesanalmente a nanquim e normógrafo em papel vegetal, mas propunham a padronização e seriação de componentes pré-fabricados para montagem rápida em canteiro - , pode-se dizer que houve uma estranha inversão entre esses pólos. Gehry alcançou um patamar industrial de prática projetual, amparado por novas tecnologias de modelagem virtual (vindas da indústria aeronáutica) que permitem desenhos irrealizáveis por instrumentos manuais e automatizam os cálculos complexos deengenharia. Entretanto, sua profusão formal, na qual nenhuma curva repete outra, acaba por exigir uma produção ultraflexível (pré-industrial, mas hoje também pós-industrial). O resultado é que seus canteiros de obra tornam-se verdadeiras oficinas de joalheria. Não há repetição de peças, cada parte do produto é diferente da outra. Em Bilbao, por exemplo, as placas de titânio foram cortadas e aplicadas manualmente em canteiro ${ }^{32}$.Ou seja, a entrada do projeto na era digital-midiática, no caso de Gehry (mas não só), não levou a uma produção mecanizada, mas a canteiros artesanais nos quais os operários não têm, entretanto,
[31] A lembrança é de Leonardo Benevolo (Arquitetura do novo milênio. São Paulo: Estação Liberdade, 2007, p. 205).

[32] Foster, op. cit., p. 36. Mesmo arquitetos high-tech e herdeiros do racionalismo, como Norman Foster e Renzo Piano, não adotam completamente a perspectiva da produção seriada, aceitando uma profusão de peças especiais em suas obras. 
[33] Davis, Mike. "Sand, fear and money in Dubai". In: Evil paradises. New York: The New Press, 2007. Segundo Davis, os Emirados Árabes, comandados por um xeique que é ao mesmo tempo emir e CEO dos grandes empreendimentos, unificaram poder político e econômico sob um só comando, numa "verdadeira apoteose dos valores neoliberais do capitalismo contemporâneo: uma sociedade que poderia ter sido desenhada por economistas da universidade de Chicago". E alcançaram o que para os conservadores americanos era apenas um sonho: construir "um oásis de livre iniciativa sem impostos de renda, sindicatos e partidos de oposição (não há eleições)", abastecido pelo fluxo da renda petroleira em alta.

[34] Uma alta "especulativa", pois se trata de um preço que presentifica um futuro de escassez e faz uma comparação com outras aplicações financeiras, pouco tendo a ver com o custo de produção.

[35] Davis, op.cit., p. 65.

[36] Marx, O capital, op. cit., t. 1, liv. I, p. 184 e p. 203 . No caso, aniquilamento em sentido estrito: segundo Javier Montes, só em 2004, Paquistão, Índia e Bangladesh repatriaram 880 cadáveres de trabalhadores da construção civil (Ver Arquitectura viva, n. 111, Madri, 2006, p.36).

[37] Davis, op.cit., p. 65. qualquer liberdade própria ao artesão - são verdadeiros autômatos reproduzindo a cada milímetro as curvas projetadas pelo arquiteto. São peças especiais, únicas, de superfícies não pensadas originalmente para cumprir sua função estrutural - na prática, um desrespeito pela produção, tão ao gosto do capital financeiro.

O último projeto de Gehry para o Guggenheim será a nova filial do museu em Abu Dhabi, capital dos Emirados Árabes, enclave paradigmático da nova economia rentista, como bem descreveu Mike Davis33. Nessa obra, Gehry teria trabalhado sem qualquer restrição orçamentária, com o objetivo confesso de superar Bilbao, solicitação de Thomas Krens e dos magnatas do petróleo. O projeto, numa península do Golfo Pérsico (o mesmo que tem abrigado diversas outras "intervenções" do poder americano), é uma repetição das fórmulas desconstrucionistas anteriores, mas em escala muito superior - não deixando de lembrar Bagdá bombardeada. O projeto participa da transição da renda petroleira (hoje em alta ${ }^{34}$, mas, algum dia, em extinção) para as novas formas de rentismo - como parques temáticos, hotéis espetaculares, novos museus de grife, ilhas da fantasia, centros financeiros de lavagem de dinheiro etc.

A outra face de obras como essa é a extração bruta de mais-valia: os canteiros de obras nos Emirados (eo novo Guggenheim não deverá ser exceção) são verdadeiros campos de trabalho semi-escravo, povoados por imigrantes desprovidos de direitos e qualquer proteção trabalhista ou sindical.Conta Mike Davis que "o boom na construção (que emprega um quarto da força de trabalho) é transportado nas costas de um exército de paquistaneses e indianos mal pagos, trabalhando em viradas de 24 horas, seis dias e meio por semana, num calor de derreter o asfalto"35. Sem limites legais e morais que o refreiem, o capital tem como impulso natural "a sucção desmesurada da força de trabalho", até o limite da sua "exaustão prematura e aniquilamento". ${ }^{36}$

A sua reprodução social também foi planejada de modo que os operários se tornem invisíveis aos visitantes. Ainda segundo Davis,

alojamentos sombrios nas periferias, nos quais seis, oito ou até doze trabalhadores são amontoados num único quarto, em geral sem ar-condicionado ou banheiros funcionando, são necessários para garantir aos turistas a imagem oficial da cidade suntuosa, sem pobreza ou favelas. 37

Nada muito diferente do que se passou com os "candangos" na construção de Brasília, cinqüenta anos antes — com a diferença de que aqui havia a promessa de um dia tornarem-se cidadãos.

A imaterialidade das novas formas, assim, está longe de pairar no ar. Com a crise do Welfare, a nova riqueza pode livremente se assentar na velha máquina de extração sem peias de mais-valia absoluta, funcionando incansavelmente para ampliar a acumulação e contrabalançar a 
tendência de queda da taxa de lucros nos setores que dispensam trabalho vivo. Os Emirados Árabes evidenciam de forma caricata um fenômeno que ocorre em escala global de forma quase generalizada. Mesmo nos países centrais, os canteiros de obra representam uma espécie de "vanguarda da desintegração" 38 do mundo do trabalho: concentram trabalhadores imigrante e de origem étnica, precarizados do ponto de vista dos direitos, com baixos salários e jornadas extensas, submetidos a riscos permanentes de acidentes e intoxicações, além do al to grau de informalidade decorrente das cadeias de subcontratação, o que também representa baixo grau de sindicalização.39

E quanto mais as diversas formas de rentismo levam a uma redistribuição perversa do lucro social, apropriando-se de fatias consideráveis dele sem levar em conta as reais proporções da produção, mais se exige dos setores produtivos que ampliem a exploração. Na mundialização financeira, formas modernas e arcaicas seguem se articulando, mas com o sinal invertido: o rentismo passa a pólo moderno, e o setor produtivo, a arcaico.

Associada a todos esses feitos, e por isso mesmo, a marca Frank Gehry atualmente explora a venda de softwares de projeto - mais uma forma de renda, a "renda do saber", devidamente protegida pela cerca das patentes. Suas obras servem como publicidade das possibilidades do software que seu escritório desenvolveu, o Digital Project (uma adaptação do CATIA para a construção civil, associada a programas de planejamento e gestão de obra), em parceria com a Dessault e com a IBM.Aempresa GehryTechnologies promete aos usuários a chance de criar com a mesma liberdade que tornou Gehry um mito, o que os outros programas não permitem. Mas se não for este o caso, a ferramenta promete ser eficiente para melhorar a produtividade em obras convencionais. Gehry já equipou os três mil profissionais do maior escritório de arquitetura do mundo, o SOM (Skidmore, Owings and Merrill), e vende pacotes para a China - o maior canteiro de obras de que já se teve notícias. ${ }^{\circ}$

\section{RUMO À DESMATERIALIZAÇÃo}

Para que nosso argumento não fique prejudicado, por ter se restringido ao mais espetacular de todos os arquitetos contemporâneos, seria necessário pelo menos indicar que ele é válido igualmente para diversas obras dos demais arquitetos-estrela de hoje - entre eles, Rem Koolhaas (no Centro de Convenções em Lille, na torre da CCTV em Pequim ou no Complexo Turístico de Jebem al Jais), Jean Nouvel (tanto na torre Agbar, em Barcelona, e sua similar, em Doha, quanto na Ópera de Dubai), Zaha Hadid (só nos Emirados Árabes: o Museu de Artes Cênicas de Abu Dhabi e as torres Signature de Dubai, co-assinadas por
[38] Tomo aqui emprestada a expressão de Roberto Schwarz para se referir ao Brasil em "Fim de século". In: Seqüências brasileiras. São Paulo: Cia. das Letras, 1999.

[39] Ver, por exemplo, a análise comparativa da pioneira "desconstrução" dos direitos sociais na construção civil na coletânea organizada por Gerhard Bosch e Peter Philips. Building Chaos: an international comparison of deregulation in the construction industry. London: Routledge, 2003.

[40] Informações obtidas no site 〈www.gehrytechnologies.com〉, acessado em 15/03/2008. 
Schumacher), Daniel Libeskind (com o seu projeto para o marco zero do World Trade Center), e tantos outros, como o mais high-tech dos arquitetos contemporâneos, Norman Foster (que deixou sua marca definitiva na City de Londres, alterando-lhe totalmente o skyline, ou projetando o maior aeroporto do mundo, em Pequim, na forma de um dragão - competindo com as estações, aeroportos e pontes do não menos requisitado por suas estruturas orgânicas ehigh-techs, a multiplicar "asas de pássaros" mundo afora, o espanhol Santiago Calatrava). Quase todos agraciados pelo Nobel de arquitetura, o prêmio Pritzker.

Para efeito demonstrativo, me detenho apenas numa dessas obras, dos arquitetos suíços vencedores também do Pritzker em 2001, Jacques Herzog e Pierre de Meuron, defensores confessos da "arquitetura de marca", como se viu na abertura deste texto, e que se tornaram famosos graças à reforma, nos anos 1990 , da usina que passou a abrigar a New Tate Modern, em Londres.

A dupla adota uma proposta estética em seus projetos num certo sentido oposta à de Gehry, utilizando formas geométricas relativamente simples como, porexemplo, no projeto da Bodega Dominus, um retângulo de espessas paredes em pedras justapostas, como gabiões, e, mais recentemente, na planta triangular do Fórum das Culturas, em Barcelona. Suas estruturas são, em geral, mais racionais, moduladas há, por assim dizer, uma promessa de produtividade, de pré-fabricação de componentes. Mas o que nos interessa aqui é o fato de os dois arquitetos suíços, mesmo nos projetos aparentemente mais contidos, explorarem progressivamente o tratamento das "peles" até seu limite.

Não custa insistir: a prevalência das superfícies em relação às estruturas é o que permite a mágica de sua desmaterialização e transformação em imagem midiática. Elas possibilitam quebrar a massa, a densidade e o peso aparentes de prédios gigantescos, como afirmou Charles Jencks ${ }^{41}$. Pois a arquitetura pós-moderna quer diminuir a massa e o peso enquanto enfatiza o volume e o contorno - "a diferença entre o tijolo e o balão", na expressão de Jameson, ou entre modernidade pesada e modernidade leve ou "líquida", nos termos de Bauman. São princípios que já estão presentes em parcela da arquitetura moderna, mas que agora são projetados em um mundo espacial inteiramente discrepante, pois já não operam de acordo com as oposições binárias modernas, explica Jameson.

Wolfgang Fritz Haug, ao analisar a abstração na estética das mercadorias, aponta justamente o elemento de superfície como componente fundamental. Segundo ele, existe uma diferenciação estrutural que permite libertar a superfície de qualquer funcionalidade que não a de aderir à mercadoria como uma pele, "lindamente preparada", não apenas como proteção envoltória mas como "verdadeiro rosto a ser visto" antes do próprio corpo da mercadoria.A superfície irá tornar-se, 
explica Haug, uma nova mercadoria "incomparavelmente mais perfeita que a primeira" e irá desprender-se desta descorporificando-see correndo pelo mundo inteiro como um "espírito colorido da mercadoria, circulando sem amarras" 42 . Ninguém estaria mais seguro contra seus "olhares amorosos", pois essa aparência abstraída (ou encenada) é sempre mais perfeita tecnicamente.

Herzog e de Meuron demonstram ousadia na experimentação de epidermes arquitetônicas cada vez mais inusitadas e imateriais. Eles passaram de uma experiência de arquitetura mais monolítica, com texturas em pedra, cobre e chapas enferrujadas, para invólucros sempre mais leves e high-tech. Sejam vidros serigrafados e suportados por aranhas metálicas, como na biblioteca de Brandenburgo; placas poliméricas que refratam a luz de forma multicolorida, no centro de dança Laban, em Londres; losangos de vidros côncavos e convexos na Loja Prada de Tóquio; ou as membranas infláveis do Allianz Arena, o estádio de Munique que sediou a abertura da Copa de 2006.

Este último é o exemplo mais acabado e espetacular dos feitos da dupla suíça. Jacques Herzog afirma que o estádio tornou-se um modelo de "projeto-logo [marca] para um país ou um clube, uma ferramenta para entrar em um mercado" 43 . O estádio é a edificação esportiva mais midiática já construída para um grande evento, com sua imagem surpreendente como um enorme pneumático iluminado (em azul,vermelho ou branco), divulgada pela mídia incessantemente para os quatro cantos do globo. As imagens da arena em construção revelam a técnica de abstração do projeto 44 - afinal, como tornar um pesadíssimo estádio em algo leve como um balão? A estrutura interna é relativamente convencional, arquibancadas em concreto armado coroadas por uma cobertura em treliça metálica. Nada muito diferente da geração de estádios construídos na Europa nas últimas décadas. Para quem acompanha as etapas da construção, a surpresa fica por conta do momento em que a superfície inflável e iluminada começa a ser aplicada sobre o corpo do edifício, produzindo um estranhamento desconcertante. Quando a cobertura membranosa passa a envolver toda a estrutura de concreto, o efeito mágico se completa. A iluminação, que nos demais estádios concentra-se em seu interior, é dirigida também para o exterior - dentro, o espetáculo esportivo, fora, o espetáculo arquitetônico, capitalizando a cidade de Munique, a alta tecnologia alemã e os próprios arquitetos. Graças ao sucesso desse projeto, a dupla H\&dM (Herzog \& de Meuron) foi imediatamente contratada para o projeto do estádio Olímpico de Pequim-2008. Mais um ativo espetacular para a arquitetura na era das marcas.

Não há,entretanto, com o que se surpreender.Como lembra Sérgio Ferro, desde o princípio o capital pôs a arquitetura a seu serviço e a transformou em forma-fetiche do objeto construído. O capítulo a que
[42] Haug, Wolfgang Fritz. Crítica da estética da mercadoria. São Paulo: Unesp, 1996, p. 75 .

[43] Apud Galiano, op. cit., p.26.
[44] O canteiro do Allianz Arena é apresentado no documentário Construindo o superestádio, de Su Turhan e Silvia Beutl (2005, 45 min.), Discovery Channel. A obra foi executada por 1,5 mil operários de 20 países diferentes, em regime de três turnos, para cumprir o prazo de inauguração exigido pela Fifa. 
[45] Compreendidas aqui não como uma ontologia, mas no sentido de uma objetividade histórica, quando se pode socialmente definir prioridades, como nos explica, por exemplo, Herbert Marcuse em $A$ ideologia da sociedade industrial: o homem unidimensional (Rio de Janeiro: Zahar, 1974, pp. 26-28).

[46] Ver o quadro descrito por Mike Davis em Planeta Favela. São Paulo, Boitempo, 2006.

Recebido para publicação em 27 de janeiro de 2008.

\section{NOVOS ESTUDOS}

\section{CEBRAP}

80, março 2008

pp. 175-195 estamos assistindo é apenas mais uma de suas metamorfoses. A novidade, agora, é que a forma arquitetônica está sendo explorada em seus limites materiais, até a inversão de seus fundamentos construtivos. A financeirização empurra a arquitetura para uma arriscada fusão com a forma publicitária e com a indústria do entretenimento.A relação clássica de forma e função expressa na tectônica do objeto arquitetônico parece estar sendo "liquefeita" para que a arquitetura possa circular mundialmente como imagem de si mesma.

De outro lado, a economia rentista está levando a arquitetura a esferas de valorização cada vez mais distantes das reais necessidades humanas45. São mínimas ou mesmo inexistentes as iniciativas desses arquitetos-estrela para procurar soluções que pudessem ao menos amenizar a condição de pobreza da imensa maioria do globo. A outra face da arquitetura de marca, rendida ao espetáculo, é um planeta em urbanização acelerada e povoado por favelas, sem solução técnica à vista e sem horizonte de transformação política. ${ }^{6}$

PEDRO FIORI ARANTES é arquiteto, doutorando na FAU-USP e autor de Arquitetura nova. (Editora 34, 2002). 